\title{
Colecionando segredos: Os aruanãs e as práticas de colecionamento no médio Araguaia
}

\author{
Rafael Santana Gonçalves de Andrade \\ Doutorando pela Universidade Federal do Riode Janeiro/ \\ Museu Nacional, Rio de Janeiro, Brasil \\ rafaelsgandrade@gmail.com
}

Resumo Pretendo discutir sobre as práticas de colecionamento que estavam vinculadas às propostas científicas de constituição do campo etnológico/antropológico. A análise remete ao colecionamento de objetos envolvidos por algum segredo ou tabu. Problematizo os colecionamentos de etnólogos/ antropólogos no médio Araguaia a partir de três situações etnográficas: de dois naturalistas alemães (1) Paul Ehrenreich, que esteve no médio Araguaia em 1888, e (2) Fritz Krause em 1908; e o caso do antropólogo estadunidense (3) William Lipkind, que esteve na região em 1938. Nos três casos foram colecionados aruanãs, nomeados pelos pesquisadores de máscaras rituais. As situações analisadas trazem à tona ideias e significados que giram em torno da categoria nativa aruanã e da categoria máscara, ambas relacionadas às práticas de colecionamento na região.

Palavras-chave: Coleções, cultura material, máscaras, segredo, Karajá. 


\section{Colecionando coisas e ideias ${ }^{1}$}

Partindo dos paradigmas que fundamentavam as situações em que as práticas de colecionamento eram constituintes do fazer antropológico, podemos notar dois regimes de produção de conhecimento que sustentavam as pesquisas: o colecionamento de ideias e o colecionamento de objetos. Fabian (2010), em uma provocação sobre a relação entre coleções e arquivos, define a escrita etnográfica como prática de colecionamento, tomando-a como um documento que faz parte dos arquivos etnográficos:

O tipo de arquivo que tenho em mente é uma coleção de textos cuja produção começa em campo, com trocas e performances registradas, e que continua com a transcrição, tradução, comentário e talvez análise formal. Desta perspectiva, o etnógrafo poderia ser visto como um colecionador que trabalha com coleções. (Fabian, 2010, p. 65)

Fabian (2010) propõe uma maneira de repensar as relações e os usos possíveis das etnografias e coleções etnográficas. Para problematizar as potencialidades das coleções etnográficas, caberia um olhar atento sobre a sua elaboração, considerando a relação entre a escrita etnográfica e o colecionamento de objetos.

Aproveito o ensejo da proposta de Fabian, mas redireciono o foco de análise das coleções para um tipo específico de "objeto"2 colecionado. Para tanto, parto do caso etnográfico dos Inỹ, grupos falantes da língua inỹrybè, conhecidos nos textos acadêmicos como os Karajá do médio rio Araguaia - no Brasil Central. ${ }^{3}$ Para ser mais específico, trato dos casos de colecionamento dos aruanãs, "seres" que se apresentam durante rituais de grupos falantes do inỹrybè que, definidos apenas pela sua dimensão material, foram colecionados e classificados como máscaras rituais desses grupos.

1 A primeira versão desse artigo foi debatida no $41^{a}$ Encontro Anual da Associação Nacional de Pós-Graduação e Pesquisa em Ciências Sociais (ANPOCS) no Grupo de Trabalho 'Coleções, colecionadores e práticas de colecionamento', coordenado pelos Professores Doutores Edmundo Pereira e Manuel Lima Filho. Agradeço ainda pelas sugestões da Profa. Dra. Renata de Castro Menezes e pela leitura cuidadosa dos colegas Marcus Bernardes, Ariel David e Gabriela Camargo.

2 Ao longo do texto as aspas duplas são usadas para problematizar os termos destacados; o itálico é usado para colocar em evidência as questões centrais formuladas e discutidas ao longo do artigo e na grafia das palavras em língua estrangeira.

3 Inỹé é a autodenominação dos grupos falantes do inỹrybè. Nas classificações linguísticas e etnológicas os inỹ são nomeados Karajá, uma denominação pejorativa que vem dos termos Caraiaúnas ou Carajáuna, usados no fim do século XVI por viajantes para remeter aos indígenas do baixo e médio Araguaia (Toral, 1992). Nas classificações mais recentes o termo Karajá é usado para se referir a três grupos: Karajá propriamente dito, Javaé e Xambioá. Houve debates sobre as particularidades dos três grupos e a estratégia de unificá-los a partir de um termo único. Contudo, prevaleceu a abordagem do grupo maior triparticionado, por compartilharem aspectos culturais bastante próximos e por falarem a mesma língua - Karajá/inỹrybè - que está classificada no tronco linguístico Macro-Jê. A região ocupada pelos grupos falantes do inỹrybè tem maior concentração de aldeias na Ilha do Bananal (TO), havendo, ainda, outras aldeias em Goiás, Mato Grosso e Pará, ao longo do rio Araguaia e do rio Javaés. 
O caso dos aruanãs está inserido nas discussões sobre os colecionamentos e práticas de coleção em uma categoria de “objetos" que de algum modo estão relacionados à categoria dos segredos. De modo geral, trata-se da especificidade de "peças" colecionadas, principalmente no momento auge do colecionamento de "objetos" indígenas na América do Sul, que cumpriam uma função ritual e/ou detinham algum significado cosmológico que as impediam de serem inseridas nos acordos e negociações de trocas de objetos com os colecionadores.

Partindo dos relatos de campo e dos trabalhos publicados por pesquisadorescolecionadores, pode-se notar algumas contradições que emergem a partir das descrições sobre o colecionamento dos aruanãs. As ideias etnológicas apresentadas nos escritos etnográficos nos levam a questionar sobre o ato de colecionar tais “máscaras rituais”.Alguns pesquisadores-colecionadores descrevem a mesma experiência de duas maneiras distintas: (1) uma versão científica, expressa na escrita etnográfica, que indica a impossibilidade de colecionar os aruanãs; e (2) outras versões consideradas menos objetivas, expressas em cartas e diários de viagem, que detalham o modo como os conseguiram para sua coleção.

A proposta é refletir sobre as práticas de colecionamento a partir dos aruanãs das coleções de museus, inspirado pela biografia das coisas como sugeriu Appadurai (2008) e Kopytoff (2008). Contudo, não se trata de construir uma linearidade processual de acontecimentos sucessivos, mas, sim, voltar-se para o passado com olhar qualificado sobre as coleções que integraram os aruanãs como um "objeto colecionado", problematizando a situação etnográfica em que foram elaboradas. Analisando, como sugere João Pacheco de Oliveira (2016, p. 33),

[...] as "condições sociais específicas que envolvem a produção de dados etnográficos", tomando como seu foco de atenção a relação entre pesquisador e pesquisados, privilegiando como áreas estratégicas os modos de interdependência e as formas de superação de conflitos.

A partir das experiências que suscitam as situações etnográficas, é possível problematizar as disposições dos atores envolvidos na retirada dos aruanãs das aldeias como “objetos de coleção”. Considerando, como sugere Pacheco de Oliveira (2016), a forma em que os conceitos e significados - inscritos no quadro de escolhas dos atores envolvidos - se correlacionam de modo interdependente para superação de conflitos. Uma vez que o campo relacional entre pesquisador e pesquisados pressupõe um espaço compartilhado no qual confluem ideias e posicionamentos, motivando-os criativamente a desenvolverem soluções e elaborarem novas estratégias para superar obstáculos que impedem o alcance de interesses emergentes; no caso dos aruanãs, como veremos, o fator complicador dos arranjos desenvolvidos na relação pesquisador-pesquisado está diretamente ligado à situação de segredo. 


\section{Os Aruanãs}

O repertório acumulado de descrições etnográficas sobre os aruanãs ${ }^{4}$ mostra como essa categoria é bastante complexa e de difícil redução conceitual. O ponto de acordo entre autores e autoras é que o termo faz referência aos ancestrais míticos dos grupos falantes do inỹrybè. Ancestrais que remontam às origens dos grupos.

De modo geral, as origens dos povos falantes do inỹrybè se deram com a saída de seus ancestrais de um plano cosmológico subterrâneo ou subaquático. Como por exemplo, o caso dos Karajá, que descrevem os aruanãs como aqueles que, no tempo mítico da origem, não saíram do berahatxi - plano cosmológico subterrâneo localizado abaixo do rio Araguaia. Contudo, é também narrado que posteriormente eles ocuparam os demais planos cosmológicos reconhecidos pelo grupo, sem perderem sua condição original de "seres" eternos/imortais. Portanto, além dos aruanãs do plano subterrâneo - berahatxi -, são identificados: (1) os aruanãs vindos do céu, plano cosmológico celeste, e (2) os aruanãs vindos do mato - no plano da superfície: wasureny (Lima filho, 1994). São esses aruanãs os que hoje dançam e cantam nas aldeias durante os rituais Karajá.

Descrições próximas também foram relatadas pelos Javaé, como são apresentadas por Patrícia Rodrigues (1993, 2008). Quanto aos Xambioá, é possível encontrar semelhantes descrições a partir de relatos do final do século XIX, registrados por Paul Ehrenreich (1948).

Quando estão visitando as aldeias, de modo geral, os aruanãs se apresentam em duplas entoando cânticos e dançando de forma sincronizada. Com algumas poucas exceções, o par aparenta ser idêntico, com variações singelas entre algum adereço ou outro. São acompanhados na dança pelas jovens solteiras que aguardam a chegada dos aruanãs em um dos caminhos que ligam o pátio da casa dos aruanãs - espaço proibido para as mulheres e crianças - e a aldeia (Andrade, 2016).

Como descreve Patrícia Rodrigues (2008), no caso Javaé, os aruanãs são herdados pelo primogênito, uma criança que passa então a ser dona de aruanã. Seria, portanto, o primogênito o verdadeiro dono do aruanã que pode transmiti-lo mais tarde para o seu primogênito (filha ou filho). Como é assinalado por Rodrigues (2008, p. 535), “os aruanãs são o bem mais precioso de uma família, repassados de geração em geração, cuja vinda ao nível terrestre é capaz de gerar um imenso prestígio tanto para o dono de aruanã, propriamente dito, quanto para os pais de aruanã."

Muitas das etnografias e trabalhos acadêmicos sobre os grupos falantes do inỹrybè tocaram, de alguma maneira, na temática dos aruanãs, cito algumas referências para o(a) leitor(a) que tenha a intenção de aprofundar nessas questões: Ehrenreich (1948), Krause (1940,1942), Lipkind (1940, 1948), Donahue Jr. (1982), Toral (1992), Lima Filho (1994), Rodrigues (1993, 2008), Andrade (2016) e Nunes (2016). A descrição apresentada é um exercício de síntese da extensa gama de trabalhos que tocam no tema dos aruanãs, mas ressalto que a complexidade do assunto exige maior aprofundamento, demonstrando as variações narrativas que assinalam as diferenças entre os grupos falantes do inỹrybè: Karajá, Javaé e Xambioá. Todavia, para a discussão que proponho, a presente descrição opera como um exercício de síntese para melhor situar as ideias discutidas ao longo do artigo. 
O processo para receberem os visitantes se dá por meio de pessoas especializadas como os hyri (os xamãs). Em suas viagens xamânicas acessam os locais onde habitam os aruanãs e conhecem seus cantos, danças, instrumentos e adornos. Essas informações são repassadas para os homens representantes da família que se comprometem a receber o aruanã sob seus cuidados. Essa entrega pode ocorrer de duas maneiras: (1) o hyri e os demais homens na casa dos aruanãs decidem se a família que já possui um aruanã vai ser capaz de sustentar a tarefa ritual de manter, alimentar e zelar do aruanã, caso verifiquem que é possível, o hyri apenas anuncia a chegada do aruanã, que já é de posse da família em questão; (2) de outro modo, é possível que um hyri entregue um aruanã novo a um filho/ filha, não primogênito, que ainda não é um(a) dono(a) de aruanã, seguindo, contudo, a mesma verificação das condições da família para manter o aruanã. A entrega de um novo aruanã inicia uma nova linha de transmissão seguindo a mesma regra da primogenitura, como assinala Rodrigues (2008) para o caso Javaé.

A relação com os aruanãs garante uma série de equilíbrios e vantagens para as aldeias. Do ponto de vista das famílias, eles garantem o crescimento e a saúde das crianças, os seus donos. No que tange aos fatores ecológicos, são entendidos como responsáveis pela sazonalidade de determinadas espécies de animais de caça ou peixes e são responsáveis pela prosperidade das colheitas nas aldeias. Os rituais de dança dos aruanãs ainda fazem circular entre as famílias vários alimentos e presentes que são parte das obrigações rituais que ficam incumbidas aos seus responsáveis.

Patrícia Rodrigues (2008) faz uma síntese comparando o entendimento que se tem sobre os aruanãs entre os grupos falantes do inỹrybè e outros grupos indígenas, ressaltando a vinculação dos aruanãs à constituição da identidade social nos grupos falantes do inỹrybè:

Os aruanãs Javaé não são simplesmente bens ou patrimônios culturais de valor transmitidos entre as famílias, como propõe [Nathalie] Pétesch para os aruanãs Karajá, de modo similar aos nomes e prerrogativas (nêkrêtch) Kayapó; nem entidades protetoras ou guardiãs das crianças frágeis, como propõe [André] Toral para os Karajá e Javaé. Eles são, antes de tudo, a forma material ou visível daquilo que os nomes/almas representam entre os Suyá,Timbirae Bororo, ou seja, relações de parentesco não baseadas na consubstancialidade. (Rodrigues, 2008, p. 527, grifo da autora)

Aruanã é a tradução para o português do termo ijasò - para os Karajá - ou irasò - para os Javaé. O termo aruanã, em português, se refere ao peixe aruanã (osteoglossum bicirrhosum), espécie da bacia amazônica comum na região do Araguaia. A tradução do termo também se deve ao fato de que em inỹrybè, ijasò ou irasò, se refere ao peixe citado, além de nomear a categoria dos ancestrais míticos. Cabe ressaltar que apesar de o nome ijasò ou irasò se referir ao peixe, a categoria é a forma genérica para se referir à multiplicidade desses ancestrais míticos que tem nomes e referências diferentes entre eles. Dito de outro modo, 
cada dupla de aruana $\tilde{a}^{5}$ que aparece dançando nos rituais tem seu respectivo nome, como por exemplo: Weru, Iraburè, Ijasòura, Txureheni, entre outros.

De todo modo, aruanã não significa máscara, a relação entre os dois termos é uma proposta de "tradução" de outra ordem, mais próxima das interpretações antropológicas. Trata-se de descrições que apresentam os rituais de dança dos aruanãs como uma dança de mascarados, como foi registrada desde as primeiras etnografias sobre os grupos falantes do inỹrybè. Não pretendo aprofundar aqui nessa complexa categoria, mas apenas esboçar sua centralidade no que se tem produzido sobre esses grupos.

Figura 1 - Aruanã - Weru Ijasò - durante o hetohokỹ da aldeia Santa Isabel do Morro

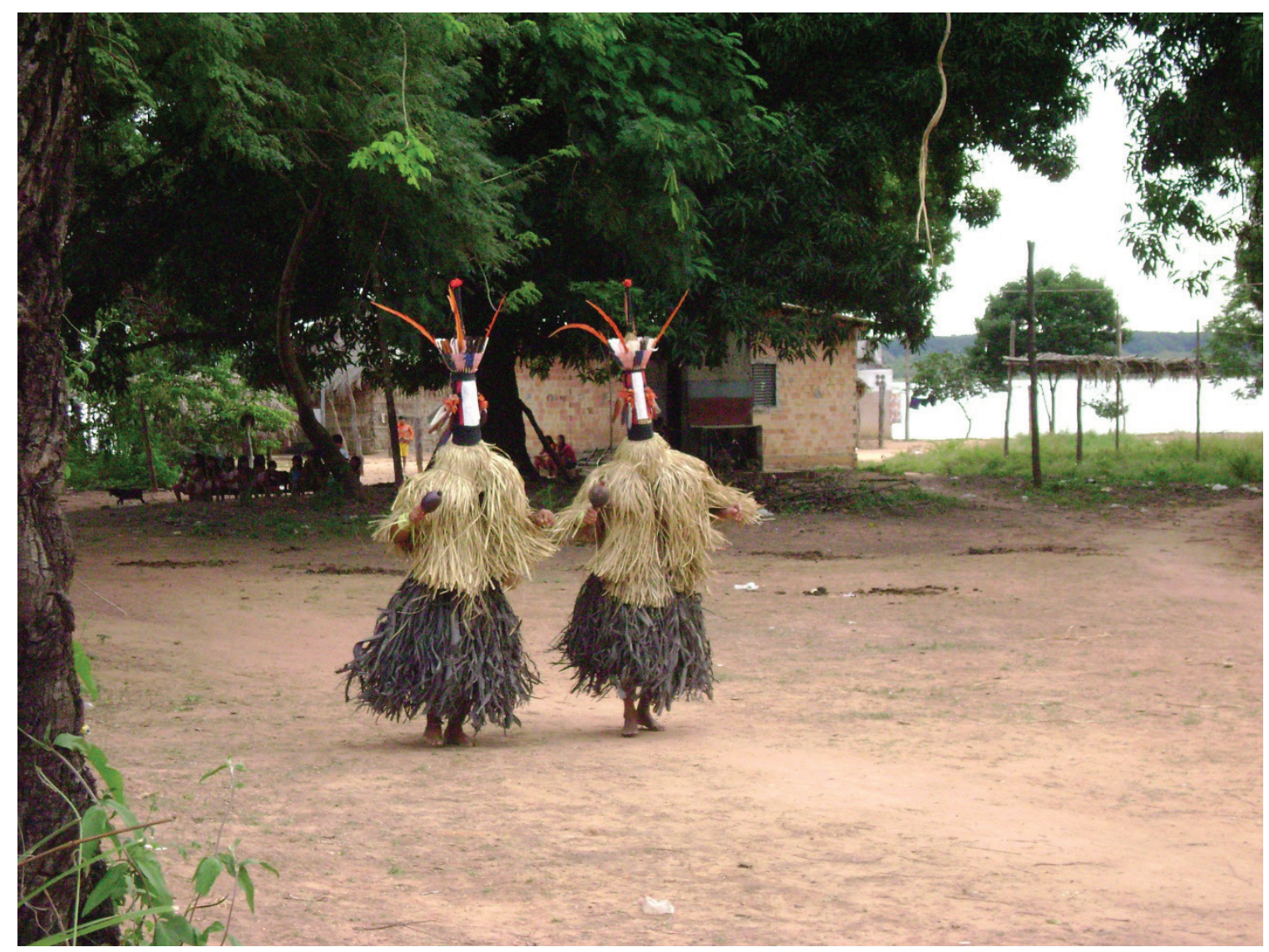

Fonte: Gustavo de Oliveira Araújo, Aldeia Santa Isabel do Morro (TO), março 2015.

\section{As práticas de colecionamento e os Aruanãs}

Em um levantamento de Sonia Ferraro Dorta (1992), a autora aponta que há coleções inỹ em pelo menos 17 museus fora do Brasil, em países como: Itália, Suécia, Alemanha,

5 Optei pelo uso do termo traduzido, aruanã, devido às diferenças linguísticas entre os grupos falantes do inỹrybè, sendo ijasò o termo iñ̃-Karajá e irasò o termo inỹ-Javaé. Tendo em vista que o presente artigo versa sobre práticas de colecionamento que atravessam os três grupos: Karajá, Javaé e Xambioá, o uso do termo na sua versão traduzida - aruanã - ressalta o caráter comum entre os grupos sem optar pela forma gráfica específica de um único grupo. 
França, Suíça, Espanha e Estados Unidos, tendo como recorte para o levantamento o período de 1650 a 1955. Já no Brasil, para o mesmo período, a autora localizou coleções inỹ em instituições como: Museu de Arqueologia e Etnologia da USP, Museu do Índio da FUNAI e Museu Nacional da UFRJ. Para além do levantamento citado, pude confirmar que há ainda coleções etnográficas inỹ depositadas no Museu Antropológico da UFG, Centro Cultural Jesco von Putkammer da PUC-Goiás e Museu Paraense Emílio Goeldi no Pará (Lima Filho, 2012).

Dentre a vasta gama de "objetos" da cultura material iñ̃ em coleções de museus, é possível encontrar os aruanãs, nomeados e classificados como "máscaras rituais", usadas pelos Karajá, Javaé ou Xambioá. Os aruanãs ocupam acervos de museus por meio dos colecionadores ao menos desde o século XIX.

Sobre o colecionamento dos aruanãs, André Toral faz um breve apontamento:

Antropólogos e coletores etnográficos profissionais, ansiosos por adquirirem tais máscaras, conseguiram-nas historicamente em operações furtivas, com máscaras envoltas em cobertas sendo embarcadas de noite e em segredo na canoa dos compradores. Foi assim que procederam os alemães Paul Ehrenreich e Fritz Krause e o americano Francis Gow-Smith, que conseguiram tais máscaras em 1888, 1908 e 1925, respectivamente, para museus de Berlim, Leipzig e Nova York. Ignoro como foram obtidos os ijasò também existentes em museus de Genebra, São Paulo (Acervo Plínio Ayrosa da Universidade de São Paulo) e Rio de Janeiro (Museu Nacional da Universidade Federal do Rio de Janeiro). (Toral, 1992, p. 163)

Os relatos sobre as expedições do século XIX até o início do século XX no médio Araguaia indicavam que dinheiro, ferramentas (enxadas, machados, pás), miçangas e utensílios gerais (pentes de madeira, panelas de metal, talheres e roupas) eram usados como moedas de troca pelos colecionadores. Contudo, no que diz respeito às "operações furtivas", como definiu Toral, os aruanãs - pelas particularidades que os envolviam demandaram esforços mais elaborados do que previam as trocas comuns feitas para a aquisição de objetos de coleção.

Os aruanãs são normalmente elencados pelos relatos como "objetos" de difícil acesso. É mais comum encontrar detalhes sobre a sua aquisição quando a investida foi bem-sucedida e sem grandes transtornos. Paul Ehrenreich (1948), naturalista alemão que realizou expedições em nome do Museu de Berlim no médio Araguaia em 1888, descreve os métodos que usou para consegui-los:

Foi graças à ajuda do chefe Pedro Manco que pude trazer felizmente algumas das máscaras mais interessantes. Sem a intercessão dele, dificilmente se teria vencido a supersticiosa desconfiança dos membros da tribo, pois uma série de viajantes, sobretudo o próprio Spínola, haviam cometido a imprudência de profanar êsses objetos sagrados. [...]. (Ehrenreich, 1948, p. 77)

Na sequência do texto, Ehrenreich (1948) apresenta algumas das especificidades dos aruanãs para os inỹ e menciona a relação deles com os segredos guardados pelos homens. 
Dito isso, Ehrenreich (1948) retoma seu relato sobre os métodos empreendidos para conseguir os aruanãs. Segundo ele, Pedro Manco (um cacique iñ̃-Xambioá) lhe disse que o segredo havia deixado de ser um costume entre os inỹ. Mas, mesmo assim, o líder iny toma as precauções necessárias e esconde as "máscaras mais interessantes" na mata para desapercebidamente serem levadas até a embarcação do naturalista alemão.

[...] Não obstante, não nos permitiram levar sem mais nem menos as máscaras encontradas na mata, porque julgavam haver mulheres na proximidade. Para transportar as máscaras ao nosso acampamento, foi preciso que os nossos camaradas as trajassem especialmente para êste fim. (Ehrenreich, 1948, p. 77)

A incoerência, no entanto, se apresenta no momento em que a categoria aruanã é reduzida de uma condição social e cosmológica, como é apresentada pelos inỹ ao naturalista, para o status de "máscaras interessantes", passíveis de complementar a coleção etnográfica do pesquisador. No que toca ao repertório de ideias que Ehrenreich nos apresenta, seu texto explica que os segredos guardados pela casa dos aruanãs, sob a mínima possibilidade de serem revelados - como a arriscada situação das "máscaras" na embarcação do naturalista -, poderiam gerar intensos conflitos internos para os inỹ e no limite, levando em consideração o anúncio catastrófico das narrativas míticas ser o motivo para a morte de todos os iny daquela aldeia.

O tabu que envolve os aruanãs dificultou significativamente o seu colecionamento, como é o caso das experiências de outros viajantes, classificadas por Ehrenreich como imprudentes "profanações de objetos sagrados" (1948, p. 77). O naturalista cita o caso de Aristides Spínola, ${ }^{6}$ que invadiu a casa dos aruanãs a fim de levá-los como objetos de coleção.

A situação violenta de invasão e tomada dos aruanãs é apresentada por Ehrenreich como algo recorrente no século XIX. Como o autor indica, tais práticas estavam mais relacionadas às propostas das expedições organizadas para fins de reconhecimento do território e questões administrativas e militares do Estado.

As coleções elaboradas nessas condições chamam atenção pelas práticas violentas atreladas ao modo de dominação colonial-imperial, atendendo aos interesses nacionais de formação e consolidação dos Estados por meio do espólio alheio. Em outras palavras, corresponde à face violenta da "cultura e autenticidade possessivas do ocidente" em suas práticas de colecionamento, como define James Clifford (1994, p. 71).

A situação limite do tipo de violência citada não torna menores os eventuais conflitos e problemas que suscitam as práticas científicas/acadêmicas na formação de coleções, como as realizadas por Ehrenreich. Mas é preciso assinalar que são situações diferentes. No caso exposto pelo naturalista alemão, sua saída, distinta das investidas violentas à casa dos aruanãs, foi o diálogo - bem-sucedido, por sinal - com Pedro Manco.

6 Ehrenreich se refere a Aristides de Souza Spínola, Presidente da Província de Goyaz (sic) de 1879 a 1880. Spínola coletou objetos de coleção durante uma expedição no rio Araguaia em 1879 (Jardim, 1880). 
O projeto de colecionamento de Ehrenreich estava inserido no modelo alemão dos estudos da Völkerkunde (ou etnologia alemã). Ligado ao museu de Berlim, mais próximo dos paradigmas evolucionistas, ele lançava mão do tipo de escrita próprio da Völkerkunde do século XIX: os relatos de viagem (Frank, 2005). Desse modo, Ehrenreich apresenta em seu texto ideias que conjugam as descrições sobre as máscaras, suas características e significados junto aos relatos sobre seus métodos de "negociação" para consegui-las. Contudo, sua atitude pressupõe que houve uma transgressão às normas êmicas, como lhes havia apresentado os inỹ, apesar de Pedro Manco sinalizar que estavam "abandonadas". Abandono que pode ser relativizado, uma vez que Pedro Manco tomou precauções rigorosas para não serem descobertos, transgredindo a suposta regra esquecida pelos inỹ.

Outro exemplo do colecionamento dos aruanãs é descrito nos trabalhos de outro naturalista alemão, Fritz Krause (1940b), que esteve entre os inỹ nos anos de 1908 e 1909, em uma missão do Museu de Leipzig. Krause relata algumas de suas estratégias de negociação para compor sua coleção de mais de 1.100 objetos levados para o Museu de Leipzig, na Alemanha.

$\mathrm{Na}$ primeira parte do seu livro, 'Nos sertões do Brasil', intitulado 'Relatório de Viagem', Krause explica que seguia com seu grupo expedicionário até o território da aldeia Furo das Pedras, próximo do atual município de Santa Terezinha (MT). A aproximação se deu com bastante cautela, pois João Cadete, o cacique inỹ-Karajá da aldeia Furo das Pedras, era temido na região, conhecido pelos ataques que comandava contra as embarcações dos não indígenas que navegavam no Araguaia.

Ao se deparar com os iny armados com arcos e flechas, bordunas e lanças, liderados por João Cadete, Krause ordena seus companheiros que deixem à mostra o arsenal de "espingardas grandes", a fim de desencorajar qualquer ataque. Tal demonstração de força, de ambos os lados, foi crucial para evitar o confronto direto. Krause, depois de uma conversa amigável, viu que era possível armar acampamento e prosseguir com as negociações com os $i n \tilde{y}$, sobretudo para conseguir mais objetos para sua coleção.

Sobre os aruanãs, Krause conta como conseguiu, com bastante cautela, entrar em acordo como cacique João Cadete:

Pelas 8 horas [da noite] arriba súbito à praia, rangendo, uma canoa; cinco índios aproximam-se da fogueira. É o cacique João com os seus homens. Contam em voz baixa terem máscara (ioonî) na canoa, pretendendo ir no dia seguinte à aldeia, para dançarem e trocarem gêneros alimentícios. Voltarão à noite, e as máscaras ficarão guardadas no mato. Peço que mas mostrem; são trançadas de folhas de palmeira, tendo feição de grandes cartuchos de papel com duas aberturas para os braços acima da borda inferior. Não consigo convencer os índios a exibirem uma dança. Receiam evidentemente que na aldeia defronte se ouça alguma coisa, o que não pode ser. Dentro em pouco vão dormir todos, fora João. Conversamos ainda, e eu negocio com ele sobre a compra das máscaras. Ele promete vende-las, mas lança ao mesmo tempo olhares tímidos para os seus companheiros, como não tendo coragem de fazer negócio com o conhecimento deles. (Krause, 1940b, p. 144) 
O olhar desconfiado de João Cadete em direção aos seus companheiros inỹ, durante as negociações com Krause, assinalam o risco daquela "negociação". Mesmo com desconfiança, como descreve Krause, os aruanãs foram escondidos no mato por João Cadete, a fim de evitar o risco de serem vistos por mulheres ou crianças. Em seguida, os aruanãs foram cuidadosamente transportados para o barco de Krause, de maneira semelhante ao processo que relatou Ehrenreich vinte anos antes.

Na segunda parte da publicação, intitulada de 'Análise Científica', no tópico 'comércio, dinheiro, medidas', Krause (1942) aponta noções de valor e mercadoria a partir de objetos trocados entre ele e os iny. Nesse rol de objetos elencados é sublinhado que "em caso algum [os iñy] vendiam máscaras de dança” (Krause, 1942, p. 161), contradizendo seu enunciado anterior, no 'Relatório de Viagem', que detalha a aquisição das máscaras por meio de negociações com João Cadete.

Tanto no caso de Ehrenreich quanto no de Krause, os paradigmas que amparavam suas práticas de colecionamento estavam coerentes com a proposta das missões científicas que representavam. A cultura material era central nos "manuais" metodológicos dos naturalistas alemães. Krause, por exemplo, dedica 81 páginas de sua análise científica para versar sobre os adornos, armas, brinquedos de criança e outros objetos, enquanto destina em torno de 12 páginas para tratar de relações sociais. Colecionar, para esse tipo de análise, era fundamental, tanto da perspectiva analítica quanto dos projetos museográficos dos museus alemães.

Ávidos por "provas concretas", os objetos eram - para os naturalistas - dados cruciais para a produção de conhecimento. A disposição que tinham para registrar os argumentos e restrições dos inỹ sobre os aruanãs não diminuía o compromisso dos pesquisadores com a objetificação: reduzindo a categoria aruanã à condição de "máscaras interessantes", objetos do mais alto valor científico para compor os acervos dos Volkerkunde Museum de Berlim e Leipzig.

Ehrenreich (1948) chega a analisar os aruanãs classificando-os como principais componentes de rituais animistas entre os inỹ, o que para ele - tendo em vista sua ligação aos paradigmas evolucionistas - compreendia "a forma mais rudimentar da vida religiosa" (Ehrenreich, 1948, p. 70). Krause (1910), por sua vez, se dedicou mais ao assunto. Ligado às vertentes do difusionismo alemão, analisou com maior profundidade as "máscaras". A análise dos aruanãs foi seu primeiro esforço analítico publicado na Alemanha, depois de retornar do Brasil. Apontou padrões e mudanças quanto às formas e tipos diferentes de "máscaras" (Krause, 1910).

Outra situação em que se deu o colecionamento dos aruanãs foi conduzida por William Lipkind. Antropólogo estadunidense que chega à ilha do Bananal trinta anos depois de Krause. Sua viagem para o Brasil é mediada pelo acordo informal de pesquisa, estabelecido na época, entre o Museu Nacional (atualmente integrado à Universidade Federal do Rio de Janeiro) e a Universidade de Columbia, nos Estados Unidos (Lima Filho, 2017). 
Lipkind morou com os Karajá, acompanhado de sua esposa, entre 1938 e 1939, tempo em que reúne uma significativa coleção etnográfica. ${ }^{7} \mathrm{O}$ colecionamento dos aruanãs se deu a partir da inserção de Lipkind em uma aldeia Javaé, no lado oriental da Ilha do Bananal, sendo depositada no Museu Nacional em 1939, antes de retornar para os Estados Unidos.

Segundo os cadernos de campo, diários e cartas de William Lipkind - analisados por Lima Filho (2017) -, o antropólogo estadunidense retornou do campo como um "pajée" Javaé, termo estampado em jornais da época que relatavam sobre a sua chegada em Belém (PA). Lima Filho explica que Lipkind, em cartas trocadas com o antropólogo Franz Boas, afirmava que havia se tornado um xamã Javaé, realizando o sonho de seu pai de vê-lo tornar-se médico (Lima Filho, 2017, p. 12). Quanto às descrições mais detalhadas sobre a formação da sua coleção etnográfica, pouco ficou registrado. Mas a iniciação xamânica de Lipkind oferece pistas sobre as condições para retirada dos aruanãs da aldeia Javaé onde realizou seu trabalho de campo.

Lipkind, inserido na proposta teórico-metodológica da antropologia culturalista de Franz Boas, faz um trabalho de campo significativamente diferente dos naturalistas. Prioriza prolongadas estadias nas aldeias inỹ, ao invés das grandes expedições alemãs que percorriam todo o rio fazendo visitas breves às aldeias que encontravam.

O antropólogo estadunidense promove sua pesquisa a partir dos "quatro campos" propostos por Boas e, ao invés do compêndio exaustivo dos naturalistas, volta seus esforços para estudos de linguística, arqueologia e de antropologia física e cultural (Stocking Jr., 2004). Durante sua pesquisa fez escavações de cemitérios inỹ-Karajá, na aldeia Fontoura, onde conseguiu alguns objetos arqueológicos para sua coleção; em suas anotações de campo fez extensos registros linguísticos do inỹrybè e algumas breves anotações de antropologia física; e, em suas duas únicas publicações sobre os inỹ, apresentou dados sobre a cosmologia e organização social do grupo (Lipkind, 1940, 1948).

A abordagem culturalista de Lipkind sustentava teoricamente sua prática de colecionamento somando o fator inexorável da aculturação dos povos ao potencial científico da cultura material. Colecionar objetos e construir uma representação material da vida das populações estudadas também era o meio viável para garantir registros sobre grupos que desapareceriam, segundo as teorias da aculturação. Essa abordagem tomava a cultura como algo passível de perda quando em contato com sociedades mais "complexas", no caso as sociedades nacionais envolventes (Schaden, 1969).

Durante a segunda parte do seu trabalho de campo, Lipkind se fixa em uma aldeia Javaé do lado oriental da ilha do Bananal. Suas notas e cartas indicam que o período nessa aldeia foi prolongado o suficiente para estabelecer relações mais sólidas com os iñy, ganhar confiança e espaço no grupo. Nesse contexto, Lipkind inicia sua especialização nas práticas xamânicas inỹ (Lima Filho, 2017).

7 A coleção William Lipkind do Museu Nacional/UFRJ foi alvo de estudo por uma equipe que atuou no Setor de Etnologia e Etnografia da instituição e publicou trabalhos a partir do esforço coletivo (Lima Filho, 2017; Ewbank; Gripp, 2016; Andrade, 2016; Ewbank, 2017). 
A mudança de paradigma e a metodologia de pesquisa de campo realizada por Lipkind delineia outra situação etnográfica que possibilita relações significativamente diferentes entre Lipkind e os inỹ, como é sugerido pela sua iniciação xamânica.

De todo modo, diferente das rápidas negociações entre caciques e naturalistas, Lipkind, durante seu longo período na aldeia, teve condições de construir relações com os Javaé que lhe renderam ao menos 21 "máscaras rituais" (aruanãs), quantidade de "máscaras" registradas na documentação do Setor de Etnologia e Etnografia do Museu Nacional/ UFRJ referentes à coleção William Lipkind. Não há registros sobre como se deram as negociações ou trocas para se obter as "máscaras", mas é possível assinalar como o campo prolongado e o aprendizado da língua possibilitaram novos modos de se relacionar com os "interlocutores" para a então retirada dos aruanãs da aldeia.

Desse modo, pode-se ressaltar, a partir da situação etnográfica em que Lipkind se encontrava, duas concepções quanto aos aruanãs: (1) máscaras a serem colecionadas; e (2) a complexa categoria diretamente ligada ao equilíbrio da organização social inỹ. As condições de campo de Lipkind possibilitaram acesso a conhecimentos sobre aruanãs que assinalavam a sua centralidade na organização social inỹ, o que já havia sido anunciado pelos naturalistas mesmo com suas breves estadias nas aldeias. A despeito disso, uma carta de Lipkind endereçada à antropóloga Ruth Benedict reforçava a redução dos aruanãs a única condição de máscaras/objetos. Na carta ele se refere às "máscaras" como "objetos valiosos" que poderiam ser vendidas por um bom preço a um colecionador em São Paulo (SP) (Lima Filho, 2017). Desse modo, sua visão dos aruanãs como objetos é reafirmada por meio da lógica mercantil ou do objeto como mercadoria.

Afinal, as intenções científicas - como as propostas de uma salvaguarda das culturas humanas ou a produção de conhecimento qualificado - estavam acompanhadas, como no caso de Lipkind, pelo potencial de valor financeiro das coleções, o que era um fator previsto e calculado pelos pesquisadores/colecionadores. Colecionar também era uma maneira de financiar pesquisas. Sendo, portanto, a venda de parte das coleções etnográficas uma prática comum do período de grandes colecionamentos (Pacheco de Oliveira, 1987).

Apesar dos tabus e segredos que envolviam os aruanãs, o projeto acadêmico de Lipkind não perdeu força, ao contrário, era um fator de considerável relevância diante da situação que ele vivenciava em campo, de modo que os aruanãs foram por ele levados da aldeia e integrados a sua coleção.

O ensejo lançado pelas práticas de colecionamento apresentadas nos leva a refletir sobre a condição ambígua que atravessa o colecionamento nas situações etnográficas elencadas. O ato de colecionar os aruanãs conduzido por Ehrenreich, Krause ou Lipkind, indica com mais clareza as várias disposições envolvidas nas relações entre pesquisadores e pesquisados. Trata-se de situações que esboçam um complexo quadro de ambivalências nas práticas de colecionamento apresentadas até aqui. 


\section{Ambivalência e disposições nas práticas de colecionamento}

O caso dos aruanãs aponta para perspectivas contrárias ou conflitantes a partir dos relatos apresentados por Ehrenreich, Krause ou Lipkind. As situações em que o colecionamento ocorreu evocam categorias distintas mobilizadas a partir de diferentes pontos de vista: aruanãs ou máscara.

Se partirmos apenas de alguns enunciados que falam a partir da categoria de "negociação", como apresentada pelos naturalistas e enfatizada nas intenções de Lipkind em vender as "máscaras preciosas", os aruanãs seriam reduzidos à condição de mercadoria, no sentido que propõe Appadurai (2008). Nesse caso, numa perspectiva processual, as relações entre os colecionadores e alguns inỹ possibilitariam que os aruanãs saíssem de uma condição singular - "sagrada” - para condição de “objeto comum” passível, portanto, de ser negociado em uma troca mercantil.

Se pensarmos a condição de mercadoria como o "objeto" possível de ser trocado em um determinado estágio de sua vida, podemos relacionar o conceito com a proposição que qualifica o aruanã como máscara de coleção. O conceito de mercadoria, como proposto por Appadurai (2008, p. 27), sugere pensar que "a situação mercantil na vida social de qualquer 'coisa', seja definida como a situação em que sua trocabilidade (passada, presente ou futura) por alguma outra coisa constitui seu traço social relevante". Chegar à condição de objeto de coleção se deu por meio de negociações bem-sucedidas ou de um acordo bem articulado que permitiu a retirada dos aruanãs das aldeias para comporem acervos de museus. De todo modo, os aruanãs como máscaras de coleção ou máscaras preciosas são classificados como objetos, sejam para fins científicos de estudos, para serem vendidos a outros colecionadores/museus, ou para serem expostos/permutados em/entre instituições de ensino/pesquisa.

Por outro lado, os aruanãs, como são descritos pelos grupos falantes do inỹrybè (como apresentado nas etnografias), estariam em uma posição que, idealmente, os preservariam fora de negociações. Os aruanãs, por uma operação cultural, estariam em uma condição singular que os impede publicamente de serem mercantilizados. Trata-se, na perspectiva de Kopytoff (2008), de um mecanismo cultural de contenção do processo incontrolado de mercantilização. A singularização, como propõe Kopytoff, é parte de uma operação cultural de distinção que desencoraja o processo anticultural da mercantilização excessiva.

Partindo de uma leitura etnográfica da questão, Patrícia Rodrigues (2008) ressalta que os aruanãs estão ligados ao eterno, são o corpo fechado. Representam o modelo ideal do verdadeiro parentesco, no qual não existem relações, gênero, passagem do tempo, trocas ou mudança. Os aruanãs são a fixidez e a eternidade. Tendo em vista a transição mítica da saída dos inỹ do mundo ideal subterrâneo para o plano terrestre, em que há a mudança, o tempo, as relações, as trocas e a morte (corpo aberto). Os aruanãs representam a possibilidade de manter o contato com o mundo ideal da fixidez e eternidade, como relatado nos mitos. Daí a sua singularização e o tabu que os envolvem, impossibilitando a sua comercialização/troca. 
Inserir os aruanãs em trocas, como as que foram feitas com os colecionadores, seria uma contradição na medida em que o estatuto da troca entre os iny - como assinala Rodrigues (2008) a partir do caso Javaé - está relacionado às mudanças e efemeridades do plano terrestre, características constituintes de um polo oposto à eternidade e imortalidade intrínsecas aos aruanãs. A troca é uma operação que se refere às mudanças, às relações, ao perecível, ao efêmero. Como ressalta Rodrigues:

A mudança é conceituada, portanto, em termos de reciprocidade com a exterioridade, seja na forma interna de troca de mulheres, responsável pela abertura dos corpos e o início da morte, ou na forma externa de trocas com os outros povos diferentes, responsável pelas mudanças culturais. A reciprocidade não é percebida aqui apenas como um mecanismo que constitui e perpetua a estrutura social, como em Lévi-Strauss, mas como o próprio vetor das transformações históricas da estrutura, como a essência de uma "desestrutura". (Rodrigues, 2008, p. 504, grifo da autora).

Acompanhando tal ordenamento preestabelecido é possível perceber como estão estruturadas as regras e segredos que envolvem os aruanãs. Que caso sejam transgredidas, podem levar a consequências catastróficas ou penalidades bastante severas ao(à) transgressor(a), questão implícita nos relatos que indicam o desconforto e a cautela dos líderes inỹ ao entregarem os aruanãs para os colecionadores.

Cabe ressaltar, portanto, que não se trata de uma única explicação ou conceito por trás dos aruanãs que explicaria o seu colecionamento. Dito de outro modo, não é um processo linear em que sai da categoria êmica - aruanã - e passa para a categoria de "máscara"/ "objeto", possibilitando a retirada dos aruanãs das aldeias. Trata-se de um processo mais complexo, em que diferentes ideias estão mobilizadas ao mesmo tempo e não são necessariamente excludentes entre si ou indicam momentos distintos. Portanto, é preciso entender melhor não as mudanças de concepções, mas as várias motivações e disponibilidades dos atores envolvidos no momento do colecionamento.

Os exemplos de colecionamento dos aruanãs apresentados até aqui suscitam questões próximas as que foram levantas por Deana Jovanovĩy. A autora sugere que "o foco antropológico nas disposições das pessoas (mutuamente opostas) abre mais possibilidades para capturar as relações de poder no estudo das contradições, do que o foco nas proposições e enunciados" (2016, p. 1).

O colecionamento dos aruanãs, de algum modo, pressupõe "negociações" e acordos, como sugerem as contradições nas etnografias citadas. As situações etnográficas, em que ocorrem o colecionamento, são atravessadas por diferentes éticas.A formação das coleções pressupõe uma relação pesquisador-pesquisado(s) em que é possível diferenciar regimes de valor estabelecidos ou (com)partilhados a partir das diferentes práticas de colecionamento. Outrossim, ao mesmo tempo em que o colecionamento dos aruanãs assinala essas especificidades, é possível cotejar os casos analisados e extrair duas ideias centrais que atravessam as diferentes práticas de colecionamento dos aruanãs: (1) os aruanãs como 
identidade social (Rodrigues, 2008); e (2) o objeto colecionável ou máscaras, na classificação dos pesquisadores.

Para entender melhor a relação entre a demanda dos colecionadores e a atitude dos caciques ou lideranças inỹ é preciso recuperar algumas discussões sobre a relação dos grupos falantes do inỹrybè com a história. Patrícia Rodrigues (2008) explica que os Javaés se compreendem como o Povo do Meio, em referência a dois polos extremos relacionados ao "rio acima" e "rio abaixo" que representam, respectivamente, o fechamento completo à exterioridade e a abertura completa à exterioridade. De modo a formar uma oposição entre: um primeiro polo, que configura o total controle por meio de relações totalmente fechadas ao Outro; e, um segundo polo, que configura o descontrole total por meio de relações completamente abertas ao Outro. Como ressalta Rodrigues:

\begin{abstract}
A história do Povo do Meio é uma história de mediação ou esforço consciente de controle, ao longo do tempo, desses dois modos extremos de relação com a alteridade, que se referem tanto às relações internas (trocas de irmãs) quanto às externas da sociedade (trocas com outros povos, que podem ser os Wêrè ou os não-índios, mais recentemente).A interação permanente e paradoxal entre os extremos de identidade e alteridade constitui a historicidade intrínseca da própria estrutura social, que encontra sua forma entre o fechamento e a abertura absolutos. As antigas estratégias de manutenção do mesmo, operadas na caminhada simbólica rio acima, convivem em contradição com as forças de mudança, que caminham na direção do rio abaixo e que podem ser mais ou menos poderosas. (Rodrigues, 2008, p. 508)
\end{abstract}

Retomando a relação dos aruanãs com as ideias relacionadas à identidade e eternidade, ligados ao polo extremo do "rio acima", podemos notar que há semelhanças nas descrições etnográficas sobre os modos de significação entre os grupos falantes do inỹrybè. O que pode ser notado a partir das análises de Rodrigues (2008) e nas etnografias de outros pesquisadores (Lima Filho, 1994; Toral, 1992; Pétesch, 2000; Nunes, 2016). Nesse sentido, a demanda dos colecionadores surgiu como um evento diacrônico que colocava os caciques ou lideranças diante de uma escolha a ser feita. Contudo, longe de uma simples decisão, tal demanda seria avaliada sob o ideal do "meio termo" entre a abertura que pressupunha a troca (relação com a alteridade) e o fechamento intrínseco aos aruanãs, que rege as regras da sua impossibilidade de troca (não relação com a alteridade).

Diante da demanda dos colecionadores, a abertura dos caciques para negociação demonstra a disposição dessas lideranças para tratar os aruanãs como "objetos", passíveis de serem entregues aos colecionadores. Contudo, essa mesma abertura é tencionada e colocada em questão pelo tabu que rege os aruanãs, uma vez que estão resguardados pela posição de "corpos fechados" e eternos, relacionados à sua condição de ancestrais míticos. Apesar da troca ser uma abertura prevista do modo de relações com a alteridade, todas as precauções são tomadas pelos caciques no momento de entrega dos aruanãs, por se tratar de um tipo de troca "não praticada". 
Dito de outro modo, não se trata de uma simples redução à condição de "objeto", mas de uma meticulosa e complexa operação cultural diante de eventos diacrônicos, como a demanda dos "não indígenas", que consequentemente exigiu decisões que oscilavam em um nível intermediário entre os polos idealizados da completa abertura (troca descontrolada) e do total fechamento (não troca). Mais do que a explicação de uma operação inỹ diante das demandas dos colecionadores, vale ressaltar que a retirada dos aruanãs das aldeias - guiado por essa complexa operação cultural - foi conduzida com cautela e precauções tanto pelos caciques quanto pelos pesquisadores. Agindo ambos de maneira obtusa com o receio de que os demais inỹ percebessem o que estava acontecendo.

Como sugere a noção de ambivalência apresentada por Deana Jovanoviỹ (2016), a ideia não é pensar os enunciados isoladamente, tomando-os como contradições ou ambiguidades nas etnografias dos colecionadores. Se levarmos em conta uma operação lógica racional é possível perceber nos textos as ambiguidades e contradições dos autores ao desenvolverem descrições sobre os aruanãs e seus respectivos colecionamentos. Mas, se, por outro lado, focarmos no exercício de retomar a situação etnográfica em que se deu o colecionamento dos aruanãs, saindo da análise restrita dos enunciados e avançando para as disposições dos atores envolvidos, podemos verificar as múltiplas posições, ideias e pensamentos que emanam dos atos de colecionamento citados, chegando ao quadro ambivalente em que tanto as ideias de aruanã ou de máscara são conceitos presentes na relação entre os colecionadores e lideranças inỹ, e não apenas conceitos contrapostos que sustentam intenções contraditórias.

Em suma, o objetivo não é reduzir, por meio da noção de ambivalência, a situação a um par conceitual encerrado em seu duplo conceito de: (1) aruanã e (2) máscara, como se fossem duas definições fechadas ou acabadas. Como a ambivalência tende a se apresentar em uma versão binária - a coexistência de duas formulações sobre a mesma coisa/ situação -, aproveito o ensejo lançado por Michael Lambek (Berliner et al., 2016) sobre a incomensurabilidade das oposições binárias. Lambek chama atenção para as contradições que operam por oposições binárias. $\mathrm{O}$ autor sugere que a incomensurabilidade é um dispositivo que explica como a comparação não é feita ao longo de um único padrão ou a partir de uma medida externa neutra. Trazendo o argumento para a sua relação com a ambivalência - que não se trata apenas de uma oposição, mas de uma coexistência do par conceitual -, os dois significados que coexistem, aruanã /máscara, fazem derivar outras ideias e conceitos que partem do par inicial, mas se desdobram incomensuravelmente a partir dele; ideias e conceitos que coexistem e fazem parte da relação, evidenciando ainda as formas de poder e hierarquia intrínsecas às trajetórias dos atores envolvidos no colecionamento dos aruanãs.

Niel Smelser (1998) mostra como a ambivalência está, de algum modo, relacionada às situações de dependência, que por sua vez suscita as formas de poder e hierarquia nas relações sociais. A escolha racional, que acaba se limitando a um tipo de escolha que se pressupõe livre, não consegue alcançar as especificidades que envolvem as disposições dos atores envolvidos nos casos de colecionamento dos aruanãs, como foram apresentados. 
Portanto, as disposições que levaram às escolhas tomadas pelos colecionadores e pelos inỹ envolvidos, estão conectadas a vários fatores que suscitam relações de dependência. Como sugere Smelser:

A forma de dependência pode variar. Uma pessoa subordinada em uma relação de poder é politicamente dependente; uma pessoa comprometida com uma causa religiosa ou social é ideologicamente dependente; uma pessoa apaixonada é emocionalmente dependente. De qualquer maneira, o elemento comum é que a liberdade de escolha é restringida pelo seu custo político, ideológico ou emocional. Portanto, dependência implica um certo aprisionamento. (Smelser, 1998, p. 8)

Nas situações etnográficas apresentadas é possível indicar algumas formas de dependência que atravessam as escolhas dos atores no caso do colecionamento dos aruanãs. A complexidade que compõe as dependências tem a ver com as tênues movimentações entre os comprometimentos assumidos e as disponibilidades de assumir riscos ao ultrapassar limites - ou chegar a eminência de ultrapassá-los - a fim de atingir um objetivo específico, como supõe os casos de colecionamento dos aruanãs.

Pode-se notar, a princípio, que há uma disposição dos colecionadores para a alteridade, noção que faz parte dos "manuais" da pesquisa de campo. A fim de produzir dados coerentes é preciso ouvir e ter acesso ao ponto de vista do grupo estudado. Posição que não é só da antropologia culturalista ou das correntes teóricas contemporâneas, mas que de algum modo já fazia parte do modelo de coleta de dados empíricos da Volkerkunde alemã, afinal viajavam para conhecer o outro, registrar suas ideias, costumes e pensamentos, mesmo que não se problematizasse a dialogia, empatia ou convívio prolongado para se chegar a tal resultado. Essa disposição para o outro justifica e fundamenta as formulações etnográficas sobre a categoria aruanã, com toda a carga social e cultural que carrega.

Todavia, apesar da disposição e abertura para o outro, as instituições totais, como os departamentos acadêmicos (Goffman, 1961), pressupõem o comprometimento institucional dos seus membros, que - no caso da antropologia - se dá por meio da limitação metodológica imposta à relação pesquisador-pesquisado, de modo que a "empatia" estabelecida não ultrapasse o perigoso limite entre o "eu" e o "outro", de modo que desestabilize o objetivo fundamental da investida científica. De um ponto de vista mais amplo, conceitualmente não se encoraja, ou se imagina possível, assumir uma posição em que a trajetória do pesquisador é negada por ele mesmo.

Nas situações etnográficas elencadas, por mais que os pesquisadores/colecionadores se dispunham a entender ou acessar o ponto de vista iñ̃, seus respectivos níveis de dependência, dado pelo comprometimento institucional, enrijecia a relação estabelecida usando-a como um meio para acessar "dados empíricos", demonstrando o quanto seria impossível para os pesquisadores/colecionadores atravessarem essa "fronteira" que os separam do seu "objeto de estudo".

Do ponto de vista dos colecionadores, o comprometimento acadêmico leva tanto à formação da coleção - o acúmulo possessivo - quanto ao exercício reflexivo de 
pensar "a partir do ponto de vista do outro". A relação nós-ele, na pesquisa de campo, fica delineada pela abertura ao modo de conhecer do outro e ao mesmo tempo controlada pelo comprometimento científico da posição inexorável de pesquisador(a). De modo que a demanda dos colecionadores pelos aruanãs, apesar de objetificá-los na forma de máscaras, não nega as formulações inỹ que delineiam a complexa categoria aruanã.

Por parte das lideranças inỹ, no momento que se dispõem a entregar os aruanãs, não estão escolhendo livremente em um plano racional de opções equivalentes. É preciso entender, antes, que a noção de "corpo fechado" e eternidade às quais estão atrelados os aruanãs, configuram um campo sensível acionado pela demanda dos colecionadores. Dessa forma, a noção de segredo é importante para a decisão das lideranças inỹ, que se mostra mais evidente na cautela que tiveram durante os processos de "negociação" dos aruanãs.

O segredo é uma dimensão fundamental das relações humanas, muitas vezes classificado pelos intelectuais na chave conceitual da religião. Como define Kees Bolle (1987, p. 1), "sem o segredo não haveria religião, como também não haveria humanidade”. Como sugere Michael Taussig (2006), o segredo tem seu potencial criativo na capacidade de "ampliação da realidade", como foi proposto por Simmel (2009). Uma ampliação do real "por meio da sensação de que, por traz da aparência das coisas, há uma realidade mais profunda e misteriosa que nós poderíamos chamar de sagrada, senão religiosa" (Taussig, 2006 , p. 166). Os colecionamentos que envolveram os aruanãs estavam lidando, portanto, com essa dimensão profunda e misteriosa da realidade que em algumas etnografias foi tratada como a esfera do sagrado.

Tomando o segredo como uma influência intrínseca à escolha tomada pelas lideranças inỹ, é importante notar que suas ações são conduzidas sob o medo das consequências de suas transgressões que "exerce sua força tremenda e tremendamente criativa por meio de sua ameaça e não de sua atualização" (Taussig, 2006, p. 164). A ameaça de sofrer alguma represália de seus pares impede que os aruanãs sejam simplesmente entregues aos colecionadores. O tabu que envolve os aruanãs é o mesmo que impulsiona uma força ativa e criativa no processo decisório dos inỹ envolvidos. Em outras palavras, foi também a maneira criativa com que as lideranças inỹ atualizaram - diante do evento histórico - o possível equilíbrio entre a abertura (relação/troca) e o fechamento (não relação/ não troca) total, previstos nas metáforas do "rio acima" e "rio abaixo", como ressaltou Rodrigues (2008) para o caso Javaé.

Do ponto de vista das lideranças inỹ, é possível notar o aruanã em sua condição concreta - como “objeto". Era uma leitura/formulação pragmática sobre os aruanãs, que é contida pelo segredo e pela possibilidade de represália que poderiam sofrer pela sua transgressão. Formulação que é acionada como uma maneira possível de lidar com a alteridade que se apresentava a partir de uma leitura mediada entre os polos extremos ideais dos iny: totalmente aberto e totalmente fechado. 


\section{Desdobramentos das práticas de colecionamento dos aruanãs}

Retomando Fabian (2010), sobre a relação entre documentos e peças de coleção, é possível notar contradições na escrita etnográfica dos colecionadores dos aruanãs. Por outro lado, nota-se, nas práticas de colecionamento citadas, a coexistência dos múltiplos significados nas experiências que resultaram nas "negociações bem-sucedidas". Longe de serem significados encerrados nos repertórios culturais de cada ator envolvido - o que tornaria rígida e substancial a separação do tipo nós-eles -, a situação em que se dá o colecionamento é marcada pelo par conceitual ambivalente aruanã/máscara.

Interessante notar como as situações de colecionamento e os múltiplos significados que assumiram os aruanãs foram se desenrolando historicamente. Os inỹ têm se organizando politicamente em torno do tema dos aruanãs colecionados. Têm sido pauta de encontros de lideranças inỹ as exposições museais de "máscaras". Lima Filho (2015) relata um caso em que a reinvindicação foi feita pelos iñ̃-Karajá ao Museu Nacional/UFRJ, exigindo que fossem retirados os aruanãs de uma das vitrines da exposição "Os Karajá: Plumária e Etnografia”, inaugurada em 2012. Segundo as lideranças inỹ-Karajá a exposição dos aruanãs colocava em risco o segredo dos homens e poderia provocar uma desestabilidade social nas aldeias. As reivindicações foram atendidas pela equipe do Museu Nacional e não só as "máscaras" foram retiradas das vitrines, como também foram retiradas suas respectivas imagens dos sítios do Museu na internet.

O caso dos aruanãs é interessante pela condição em que se encontram ao serem expostos ou guardados em acervos museais. Como foi assinalado, os aruanãs estão diretamente relacionados à vida, ao eterno, ao estável. No processo ritual essa condição é garantida com a queima de sua dimensão material/concreta - máscaras. Queimar a máscara é justamente a garantia do segredo, que resguarda aos aruanãs a condição de eternos. A materialização da eternidade dos aruanãs só é possível por meio da queima secreta das máscaras, pois é ela que abre a possibilidade de que sejam sempre atualizadas a cada ciclo ritual. A máscara que é colecionada, guardada ou exposta, é colocada à prova e ao sabor do tempo, revelando a condição mutável e efêmera da matéria no plano cosmológico terrestre.

A redução que foi feita dos aruanãs à condição de máscaras colecionadas provocou uma distensão entre a sua dimensão "material" e "conceitual" - como se fosse possível separá-las. Neste sentido, a mesma operação que desestabiliza a eternidade intrínseca aos aruanãs é a que os coloca sob a condição do contingente, do movimento do tempo, da constante mudança, ideias que estão presentes nas teorias da "vida inerente às coisas" (Ingold, 2015) ou da "agência dos objetos" (Gell, 1998). Neste caso são de fato as máscarasaruanãs, em sua dimensão material/concreta, que "agem" ao motivar a ação dos atores a elas relacionados (Gell, 1998), uma vez que são exemplos evidentes da "ruptura" e da "contradição" provocadas pelo seu colecionamento.

Dito de outro modo, como prefere Ingold (2015, p. 63), as "coisas” não se desligam dos "fluxos geradores do mundo de materiais no qual elas vieram à existência e 
continuam a subsistir”. A ligação se mantém, mas ela é sustentada pela contradição que produziu no momento em que foram colecionadas as máscaras-aruanãs. Portanto, essas máscaras colecionadas, armazenadas em museus ou instituições de pesquisa, continuam provocando ressonâncias, mobilizando novas relações por meio das disponibilidades dos vários atores imbricados com as coleções: por vínculo institucional, objeto de pesquisa, projeto museográfico, posicionamento político, entre outros.

$\mathrm{Na}$ medida em que os atores se veem comprometidos institucionalmente, passam a lidar com as coleções e, consequentemente, com as trajetórias dos "objetos" - noção de trajetória e processos que estão presentes tanto nas teorias da "agência dos objetos" (Gell, 1998) quanto no "fluxo dos materiais" (Ingold, 2015). Retomando a posição ambivalente dos colecionadores que se viam entre o ofício de pesquisador e a abertura para o outro, os membros das instituições museais e os acadêmicos não lidam com essas coleções etnográficas sem acionar o quadro ambivalente partilhado pelos colecionadores dos aruanãs. Em outras palavras, quem lida diretamente com esses acervos se vê impelido - por força institucional - a levar em consideração informações etnográficas, descrições e documentações museológicas fornecidas pelos colecionadores, que colocam em questão o ponto de vista do outro de onde originaram as peças colecionadas.

Por parte dos inỹ, nota-se ainda como os museus e instituições acadêmicas têm se constituído como esferas relevantes para levar adiante suas reivindicações, construir parcerias ou catalisar suas demandas diante dos estados nacionais. Cientes da potência representativa desses espaços, a reivindicação pela retirada dos aruanãs das vitrines demonstra a disposição das lideranças inỹ em dialogar com os responsáveis e disputar politicamente por espaços produtores de representações.

A demanda pelos aruanãs não é a primeira experiência dos iñ̃ nas disputas diante de esferas de representação envolvidas com o tema do patrimônio. Os iñ̃, em parceria com a Universidade Federal de Goiás, solicitaram a patrimonialização das ritxoko (bonecas de cerâmica), e, em 2012, o Instituto do Patrimônio Histórico e Artístico Nacional registrou o modo de fazer as ritxoko como patrimônio do Brasil (Lima Filho et al., 2011).

Assim, a relação dos inỹ com a temática das coleções ou da patrimonialização demonstra a disponibilidade de suas lideranças e representantes para disputarem espaço político justo e equânime no cenário nacional. Exigir a retirada das máscaras de vitrines de museus ou fazer uma parceria com o Estado por meio do IPHAN são, como define Lima Filho, "modulações diferenciadas com as políticas patrimoniais" do Estado (2015, p. 145).

Em suma, o momento de diálogo e abertura se mostra um campo importante para se repensar as práticas museais de guarda e exposição de objetos/coisas. $\mathrm{O}$ atual momento de abertura das instituições museais ou universidades para relação com os grupos "pesquisados", anuncia a necessidade de analisar com mais profundidade os processos históricos que envolvem essas relações. No caso dos aruanãs creio ser importante levar em consideração os vários significados e noções que compõem o par conceitual aruanã / máscara, para se pensar as novas reinvindicações e demandas que vêm sugerindo a abertura institucional e o diálogo com os inỹy. 


\section{Referências}

ANDRADE, Rafael Santana Gonçalves de. Os huumari, o obi e o hyri: a circulação dos entes no cosmo Karajá. 2016. 108f. Dissertação (Mestrado em Antropologia) - Pós-Graduação em Antropologia Social, Universidade Federal de Goiás, Goiânia, 2016.

APPADURAI, Arjun. A vida social das coisas: as mercadorias sob uma perspectiva cultural. Niterói, RJ: Editora da Universidade Federal Fluminense, 2008.

BERLINER, David et al. (Ed.). Anthropology and the study of contraditions. Hau: Journal of Ethnographic Theory, v. 6, n. 1, p. 1-27, 2016 .

BOLLE, Kees W. Secrecy in Religion. In: BOLLE, Kees W. (Org.). Secrecy in Religions. Leiden: Brill, 1987.

CLIFFORD, James. Colecionando arte e cultura. Revista do Patrimônio Histórico e Artístico Nacional, n. 23, p. 69-89, 1994.

DONAHUE JR., George Rodney. A contribution to the ehnography of the Karajaindians of Central Brazil. 1982. $348 \mathrm{f}$. Tese (PhD in Anthropology) - University of Virginia,Virginia, 1982.

DORTA, Sonia Ferraro. Coleções etnográficas: 1650-1955. In: CUNHA, Manuela Carneiro da (Org.). História dos índios no Brasil. São Paulo: Companhia das Letras; Secretaria Municipal de Cultura; FAPESP, 1992.

EHRENREICH, Paul. Contribuição para a etnologia do Brasil. Revista do Museu Paulista, Nova série, v. II, p. 7-135, 1948.

EWBANK, Cecília de Oliveira. A parte que lhe cabe desse patrimônio: o projeto indigenista de Heloísa Alberto Torres para o Museu Nacional (1938-1955). 2017. 296f. Dissertação (Mestrado em História) - Universidade Federal de Santa Catarina, Florianópolis, 2017.

EWBANK, Cecília de Oliveira; GRIPP, Maria Pierro. O oculto em movimento: ressignificando uma coleção etnográfica na reserva técnica. Anais da 30ª Reunião Brasileira de Antropologia, 2016. Disponível em: <http:// www.30rba.abant.org.br/arquivo/downloadpublic?q=YToyOntzOjY6InBhcmFtcyI7czozNToiYToxOntzOjEwOiJJRF9BUlFVSVZPIjtzOjQ6IjI4MzUiO30iO3M6MToiaCI7czozMjoiMDAyZDY2ODI5YjE3NDlkOWVlYzE5OGE5YjJkZWNhMmUiO30\%3D>.Acesso em: 27 jan. 2018.

FABIAN, Johannes. Colecionando pensamentos: sobre os atos de colecionar. Mana, Rio de Janeiro, v. 16, n. 1, p. 59-73, 2010.

FRANK, Erwin Heirinch. Viajar é preciso: Theodor Koch-Grünberg e a Völkerkunde alemã do século XIX. Revista de Antropologia, v. 48, n. 2, p. 559-584, 2005.

GELL, Alfred. Art and agency: an anthropological theory. New York; London: Clarendon Press, 1998.

GOFFMAN, Eving. Asylums: Essays on the Social Situation of Mental Patients and Other Inmates. New York: Doubleday Anchor, 1961.

INGOLD, Tim. Estar vivo: ensaios sobre movimento, conhecimento e descrição. Petrópolis, RJ:Vozes, 2015.

JARDIM, Joaquim Rodrigues de Moraes. O rio Araguaya. Relatório de sua exploração pelo Major d'Engenheiros Joaquim R. de Moraes Jardim, precedido de um resumo histórico sobre sua navegação pelo Tenente-Coronel d'Engenheiros Jerônimo R. de Moraes Jardim, e seguido de um estudo sobre os índios que habitam suas margens, pelo Dr. Aristides de Souza Spinola, Presidente de Goyaz. Goyaz:Tyograhia Rovincial, 1880.

JOVANOVIỹ, Deana. Ambivalence and the study of contradictions. Hau: Journal of Ethnographic Theory, v. 6, n. 3 , p. 1-6, 2016.

KOPYTOFF, Igor. A biografia cultural das coisas: a mercantilização como processo. In: APPADURAI, Arjun (Org.). A vida social das coisas: as mercadorias sob uma perspectiva cultural. Niterói, RJ: Editora da Universidade Federal Fluminense, 2008.

KRAUSE, Fritz. Nos sertões do Brasil. Revista do Arquivo Municipal de São Paulo, São Paulo, v. 69, p. 213-232, 1940. . Nos sertões do Brasil. Revista do Arquivo Municipal de São Paulo, São Paulo, v. 70, p. 135-158, 1940 b. 
Nos sertões do Brasil. Revista do Arquivo Municipal de São Paulo, São Paulo, v. 85, p. 159-174, 1942.

. Tanzmaskennachbildungen vom mittleren Araguaya (Zentralbrasilien). Jahrbuchdes Städtischen Museums fürVölkerkundezu Leipzig III. Leipzig, 1910.

LIMA FILHO, Manuel Ferreira. Cidadania Patrimonial. Revista Anthropológicas, Recife, ano 19, v. 2, n. 26, p. 134$155,2015$.

. Coleção William Lipkind do Museu Nacional: trilhas antropológicas Brasil-Estados Unidos. Mana, v. 23, n. 3, p. 473-509, 2017.

Hetohoky: um rito karajá. Goiânia: Editora UCG, 1994.

Kanaxywe e o mundo das coisas Karajá: Patrimônios, museus e estudo etnográfico da coleção William Lipkind do Museu Nacional, RJ [manuscrito]. Goiânia: Universidade Federal de Goiás; CNPq, 2012.

LIMA FILHO, Manuel Ferreira et al. Bonecas Karajá: arte, memória e identidade indígena no Araguaia. Goiânia: IPHAN, 2011.

LIPKIND, William. Carajá Cosmography. The journal of the American Floklore, v. 53, n. 210, p. 248-251, 1940.

.The Carajá. In: STEWARD, Julian Hynes. (Ed.). Handbook of South American Indians. Washinton, 1948. v. 3.

NUNES, Eduardo Soares. Transformações Karajá: os “antigos” e o "pessoal de hoje” no mundo dos brancos. 2016. 609f.Tese (Doutorado em Antropologia) - Programa de Pós-Graduação em Antropologia Social do Departamento de Antropologia, Universidade de Brasília, Brasília, 2016.

PACHECO DE OLIVEIRA, João. Elementos para uma sociologia dos viajantes. In: OLIVEIRA, João Pacheco de (Org.). Sociedades Indígenas e Indigenismo no Brasil. Rio de Janeiro: UFRJ; Ed. Marco Zero, 1987.

O nascimento do Brasil e outros ensaios: Pacificação, Regime Tutelar e Formação de Alteridades. Rio de Janeiro: Contra Capa, 2016.

PÉTESCH, Nathalie. La pirogue de sable: pérennité cosmique et mutation sociale chez les Karajá du Brésil central. Paris: Peeters Publishers, 2000. v. 8.

RODRIGUES, Patrícia de Mendonça. A caminhada de Tanỹxiwè: uma teoria Javaé da História. 2008. 932f. Tese (Doutorado em Antropologia) - Departamento de Antropologia da Divisão de Ciências Sociais, Universidade de Chicago, Illinois, 2008.

O povo do meio: tempo, cosmo e gênero entre os Javaé da ilha do Bananal. 1993.438. Dissertação (Mestrado em Antropologia) - Programa de Pós-Graduação em Antropologia Social do Departamento de Antropologia, Universidade de Brasília, Brasília, 1993.

SCHADEN, Egon. Aculturação indígena: ensaio sobre fatores e tendências da mudança cultural de tribos índias em contacto com o mundo dos brancos. São Paulo: Editora Pioneira; Editora da Universidade de São Paulo, 1969.

SCHUMANN, Leonor; HARTMANN, Thekla. Coleções etnográficas brasileiras em Sttugart: histórico e composição. Revista do Museu de Arqueologia e Etnologia, v. 2, p. 125-132, 1992.

SIMMEL, George. A sociologia do segredo e das sociedades secretas. Revista de Ciências Humanas, Florianópolis, EDUFSC, v. 43, n. 1, p. 219-242, 2009.

SMELSER, Neil Joseph. The rational and the ambivalent in the social sciences. American Sociological Review, v. 63, n. 1, p. 1-15, 1998.

STOCKING JR., George Ward. (Org.). Franz Boas: a formação da antropologia americana 1883-1911. Rio de Janeiro: Contraponto Editora/ UFRJ, 2004.

TAUSSIG, Michael. Walter Benjamin's grave. Chicago; London:The University of Chicago Press, 2006.

TORAL, André Amaral de. Cosmologia e sociedade Karajá. 1992. 270f. Dissertação (Mestrado em Antropologia) - Programa de Pós-Graduação em Antropologia Social do Museu Nacional, Universidade Federal do Rio de Janeiro, Rio de Janeiro, 1992. 


\title{
Collecting secrets: the aruanãs and the collecting practices in the middle Araguaia
}

\begin{abstract}
I intend to discuss collecting practices that were linked to scientific proposals for the constitution of the ethnological/anthropological field. The analysis refers to the collection of objects involved by some secrecy or taboo. I question the collections of ethnologists/anthropologists in the middle Araguaia river from three ethnographic situations: two German naturalists (1) Paul Ehrenreich, who was in the middle Araguaia in 1888, and (2) Fritz Krause in 1908; and the case of the American anthropologist (3) William Lipkind, who worked in the region in 1938. In all three cases the researchers collected the aruanãs, which they called "ritual masks". The situations analyzed bring to light ideas and meanings that focus on the native category aruana and the category of mask, both related to the collecting practices in the region.
\end{abstract}

Keywords: Collections, material culture, masks, secrecy, Karajá.

\section{Coleccionando secretos: Los aruanãs y las prácticas de coleccionismo en el medio Araguaia}

\section{Resumen}

Pretendo discutir las prácticas de coleccionismo que estaban vinculadas a propuestas científicas de constitución del campo etnológico/antropológico. El análisis remite al coleccionismo de objetos envueltos por nociones de secreto o tabú. Pongo en duda el coleccionismo hecho por los etnólogos/antropólogos en el Medio Araguaia, partiendo de tres situaciones etnográficas: dos naturalistas alemanes (1) Paul Ehrenreich, que estaba en el Medio Araguaia en 1888, y (2) Fritz Krauseen, en 1908; y el caso del antropólogo estadounidense (3) William Lipkind, que estuvo en la región en 1938. En los tres casos fueron coleccionados aruanãs, llamados por los investigadores máscaras rituales. Las situaciones analizadas traen a la luz ideas y significados que giran en torno a la categoría nativa aruanã y a la categoría máscara, ambas relacionadas con las prácticas de coleccionismo en la región.

Palabras clave: Colecciones, cultura material, máscaras, secretos, Karajá.

Data de recebimento do artigo: 05/11/2017 Data de aprovação do artigo: 28/01/2018 